\title{
Study on the Key Technology of Controlling the Instability of Deep High-Stress Coal and Rock Mass and Relieving the Danger
}

\author{
Zhijing Zhang, ${ }^{1}$ Jianghong Zuo, ${ }^{1}$ and Dongji Lei $\mathbb{D}^{2}$ \\ ${ }^{1}$ Wuyang Coal Mine of Shanxi Lu'an Environmental Protection and Energy Development Co., Ltd., Changzhi City, \\ Shanxi Province 046000, China \\ ${ }^{2}$ State Key Laboratory Cultivation Base for Gas Geology and Gas Control, Henan Polytechnic University, \\ Henan Province 454000, China \\ Correspondence should be addressed to Dongji Lei; leidongji@126.com
}

Received 28 May 2021; Accepted 26 July 2021; Published 6 August 2021

Academic Editor: Wei-yao Guo

Copyright ( 2021 Zhijing Zhang et al. This is an open access article distributed under the Creative Commons Attribution License, which permits unrestricted use, distribution, and reproduction in any medium, provided the original work is properly cited.

\begin{abstract}
In order to solve the problem of stress concentration and gas overrun in the process of uncovering high gas and thick coal seam, combined with the occurrence characteristics of coal seams in Wuyang Coal Mine, the measures of "hydraulic and mechanical cavity making + steel screen pipe + surrounding rock grouting" are adopted to establish a method for mutual verification of multiple effect test indexes of residual stress, residual gas content, coal seam moisture content, and microseismic signal characteristics, and the three-dimensional accurate analysis of the influence range of hydraulic cavitation is effectively realized. By comparing and analyzing the gas extraction amount, the surrounding borehole stress change and the microseismic monitoring signals before and after the application of hydraulic cavitation technology are studied. The results show the following. (1) The pressure relief effect of the hydraulic cavity on surrounding coal decreases with the increase of distance, and the pressure relief effect is most obvious at 1.0 2.5 m, in the range of 2.5-3.5 m around the hydraulic drilling hole, the duration, rate, and amplitude of pressure relief are reduced compared with those in the range of less than $2.5 \mathrm{~m}$, while in the range of more than $3.5 \mathrm{~m}$, the effect of pressure relief is very weak. (2) During the period of hydraulic cavitation release hole, the radius of water supply to coal seam is within $1.5 \mathrm{~m}$, which accounts for $79 \%$ of coal wall area. (3) It is also a process where the stress distribution in the coal and rock body needs to be rebalanced before and after hydraulic caverning, which is often accompanied by microfracture of coal and rock mass. The analysis shows that, before hydraulic caverning, the waveform of coal and rock fracture signal has a short duration, large amplitude, and obvious signal mutation, and the dominant frequency of the signal is about $250 \mathrm{~Hz}$, with large total energy. After hydraulic caverning, the intensity of coal and rock fracture events is greatly reduced. The research results can effectively identify the influence range of hydraulic cavitation, improve the detection accuracy and efficiency of hydraulic cavitation range, effectively predict and warn the hidden danger of mine safety, and provide a reference for the work of similar mines.
\end{abstract}

\section{Introduction}

At present, China's coal mines have entered deep mining areas, and the characteristics of high gas content, strong adsorption, and poor air permeability of coal seams have more obvious constraints on the efficient mining of the mine, and because of the increase of the scale of coal mining, the impact on the environment is bigger and bigger [1]. The key to efficient mining is to improve the permeability of coal seam, realize the efficient predrainage of gas before mining, and effectively reduce the content of gas in the coal seam. At the moment, measures such as loose blasting [2-4], hydraulic slitting $[5,6]$, hydraulic punching [7, 8], and hydraulic fracturing [9-11] have been widely adopted to relieve pressure and improve reflection of coal seams. But due to the limitations of these measures, applicable conditions, such as loose blasting and hydraulic slotting easily induced by coal and gas outburst, stress, high hydraulic fracturing cracks easily closed, and hydraulic punching limited by the rigidity coefficient of coal, are susceptible to the limitation of geological structure and construction equipment; at the same time, the effect evaluation of hydraulic hole forming is 
imminent. Microseismic monitoring technology is a geophysical real-time monitoring technology that studies and evaluates the stability of coal and rock mass by using the microseismic signals generated in the process of coal rock failure under load $[12,13]$. It can effectively identify different coal and rock dynamic disaster signal types and characteristics, evaluate the stability of coal internal structure, and provide theoretical support for coal and rock dynamic disaster prevention in underground operation.

The technology of hydraulic hole punching and cavitation is to cut the coal around the drilling hole with a highpressure water jet under the condition of no one in the working face to form a larger hole, increase the exposed area of the coal body, relieve the pressure inside the coal seam, and take the cut coal out of the hole with water flow. In the process of hydraulic cavitation, a large number of coal bodies are crushed and rushed out of the borehole under the impact of high-pressure water flow, which can greatly reduce the in situ stress of coal bodies. At the same time, cavitation causes a large amount of coal caving to form several depressurized caverns with a larger diameter, which increases the exposed area of the coal seam, and forms a huge fracture network around the caverns, which provides a large space for gas migration and extraction and improves the permeability of coal seam. In addition, hydraulic perforation and cavitation make a large amount of water enter the coal body, improve the desorption rate of gas in the coal body, and further reduce the risk of coal and gas outburst [14]. Many scholars have conducted in-depth research on this. Wang and Li [5] and others conducted numerical simulation by using the field measured data and found that after the implementation of hydraulic extrusion measures in the heading face, the stress of coal body in front of the heading face was redistributed, the elasticity was reduced, the plasticity was increased, and the permeability of coal body was enhanced. Through analysis, Li [6] concluded that water injection by hydraulic extrusion can effectively reduce the gas content and gas emission in coal, greatly reducing the risk of outburst; Yang and $\mathrm{Hu}$ [7] and others pointed out that hydraulic punching in high outburst coal seam can not only eliminate the outburst risk of working face but also improve the driving speed and working environment. Liu et al. [9] and others elaborated the basic principle of hydraulic cavitation technology based on the research background of Jiulishan Mine with serious coal and gas outburst and pointed out that hydraulic cavitation technology could effectively eliminate the stress of excitation outburst, reduce the risk of coal seam outburst, and increase the driving speed of roadway by 2-3 times. Lu and others [11] used $40 \sim 60 \mathrm{MPa}$ high-pressure water jet cutting measures for gas control in Rujigou coal mine, effectively improved the coal seam permeability, increased the gas drainage efficiency by $3 \sim 6$ times, and eliminated the outburst risk in the process of mining. Zhang [15] combined theoretical analysis with the field test, studied the application effect of hydraulic hole making pressure relief and permeability enhancement technology in coal roadway bottom drainage, and showed that hydraulic hole making drilling can have the effect of pressure relief and permeability enhancement on coal body. Compared with ordinary through-layer drilling, hydraulic hole making technology increases the initial gas drainage concentration, and the influence radius of drilling also increases by one time. It can be seen that hydraulic cavitation has a good improvement and promotion effect on coal seam gas release and pressure relief, so it is extremely urgent to develop hydraulic cavitation technology to prevent coal and gas outbursts in the roadway.

The coal mining depth of the Wuyang Coal Mine of Shanxi Lu'an Group has reached more than 700 meters. With the increase of mining depth, the permeability of the coal seam itself and surrounding rock is reduced, and the amount of gas is also increasing, and there are many times of coal blasting in the excavation. In order to solve the problems of stress concentration and gas overrun in the process of uncovering high gassy thick coal seam, combined with the occurrence characteristics of the coal seam in Wuyang Coal Mine, by using the combination of "hydraulic and mechanical cavity making + steel screen pipe + surrounding rock grouting" outburst prevention technology, the mutual verification method of multiple effect inspection indexes such as residual gas pressure, residual gas content, K1 value, coal swelling deformation, coal seam moisture content, and surrounding rock deformation is established, which effectively realizes regional pressure relief, water supplement, and surrounding rock stress control. In this paper, by comparing the changes of gas drainage amount and surrounding borehole stress before and after hydraulic punching, the gas drainage effect after hydraulic punching and the activated drainage radius after stress release are studied. Combined with the microseismic monitoring technology, the whole process monitoring and comparative analysis of the spatial-temporal distribution characteristics of microseismic events before and after the measures and the dynamic response characteristics of the signal waveform are carried out, and the activated extraction radius after hydraulic cavity building is verified by contact and noncontact means, which provides a theoretical basis for preventing mine rock burst disaster.

\section{Hydraulic Cavern Engineering Test}

Wuyang Coal Mine mainly adopts 3\# coal seam, and the gas control measures are mainly prepumping coal seam gas by drilling along the seam. In daily work, there are many problems, such as a large amount of drilling engineering, the easy collapse of drilling, and the low net quantity of single hole, which directly lead to a long time of reaching the standard of drainage and then cause a serious imbalance of mining and drainage balance. The attenuation coefficient of borehole coalbed methane flow in 3\# coal seam of Wuyang Coal Mine is $0.0063 \mathrm{~d}^{-1}$, the permeability coefficient is $0.412 \sim 0.88 \mathrm{~m}^{2} / \mathrm{MPa}^{2} \bullet \mathrm{d}$, and the firmness coefficient is $f=0.2 \sim 0.5$. According to the daily underground gas content measurement results, the coal seam coalbed methane desorption speed in this area is slow, and $60-70 \%$ of the coalbed methane is comminuted desorption volume, which directly leads to low single hole drainage volume of drainage borehole. The in situ stress in this area is large, complex, and 
changeable, and it is easy to collapse after drilling. It is difficult to release the in situ stress in the drainage area and then inhibit the coalbed methane desorption, resulting in the rapid attenuation of single hole drainage volume. In view of this, it is urgent to adopt effective pressure relief and permeability enhancement technology to improve the gas drainage effect.

2.1. Engineering Principle of Hydraulic Cavitation. Assuming that the shape of the hole after hydraulic punching is still circular, when the broken coal is discharged from the hole, the diameter of the hole increases, and the radius of the pressure relief zone is as follows:

$$
\begin{aligned}
R_{x}= & \left(R_{x}+x\right) \exp \left[\frac{\left(\sigma_{r d} / \sigma_{c i}+s / m_{b}\right)}{\left(s / m_{b}\right)}\right]^{1-a} \\
& \cdot\left\{\frac{\left(\sigma_{c}-\sigma_{c r}\right)}{Q\left[(2-2 \mu) \sigma_{0}-\sigma_{r d}\right](1+\mu)}+1\right\}^{-1 /(1+N p)} .
\end{aligned}
$$

After hydraulic punching, the radius of the broken area of the borehole increases, the pressure relief area increases, the strain affects the stress change, and the stress around the borehole obviously decreases. Based on the strain-softening model of the H-B criterion, when the drilling hole is impacted by a high-pressure water jet, the strength of coal decreases. The place where the coal is thus damaged and displaced is called the crushing area. The more distant it is, the greater stress the coal body suffers, ending up going beyond its own strength. This happens in the plastic area. When the stress of the coal body is less than its own strength, the coal body will have elastic deformation within a certain range, which is called the elastic area. Therefore, the stressstrain curve of coal can be divided into an elastic stage, softening stage, and residual stress stage, and the area of corresponding coal around the drilling hole can also be divided into an elastic zone, plastic zone, and crushing zone. According to the distance from the hole, it can be divided into pressure relief zone, stress concentration zone, and original stress zone. And its distribution changes are shown in Figure 1.

In the process of hydraulic pressure relief, the stress of the coal body is released, the strength of the coal body is destroyed, the permeability of the coal body in the pressure relief area is increased, and the gas drainage rate is effectively improved. The stress around the hole drilling meets the following equation:

$$
\frac{\mathrm{d} \sigma_{r}}{\mathrm{~d} r}+\frac{\sigma_{r}-\sigma_{\theta}}{r}=0
$$

where $\sigma_{r}$ is the borehole stress, and $\sigma_{\theta}$ is the borehole tangential stress.

To sum up, the evaluation of the scope and effect of hydraulic cavity building should first examine whether it can increase the pressure relief range of drilling along the coal seam, whether it can concentrate the stress to move far away and reduce the relative stress of the coal seam around the cavity building area. Therefore, the borehole stress meter will be used to test the change of relative stress at different distances around the hole, and then, the influence range of hydraulic cavitation can be analyzed.

2.2. Engineering Design of Hydraulic Cavity Making. Combined with the actual situation of the Wuyang Coal Mine, two types of test boreholes were constructed in this study, which is hydraulic hole making boreholes and stress test boreholes. They are divided into three groups, with 5 boreholes in each group, 3 hydraulic hole making boreholes and 2 stress test boreholes. Now, 5 boreholes have been tested in the 8006 air-return roadway. During the process of drilling construction, high-pressure hydraulic punching is carried out for hydraulic hole drilling; after the construction of stress test drilling, the stress meter is installed, and the stress meter is pressed to make the flexible detection unit expand to the preset pressure of $5 \mathrm{MPa}$ and test the stress condition during hydraulic hole drilling, and the drilling is shown in Figure 2.

Drilling type: 2 stress test holes, Y1 and Y2, respectively; 3 hydraulic holes, S1, S2, and S3, respectively. Opening height: the upper row of boreholes is hydraulic hole making boreholes with an opening height of $1.8 \mathrm{~m}$; the lower row of boreholes is stress testing boreholes with an opening height of $1.6 \mathrm{~m}$. Opening spacing: nonequal spacing, as shown in Figure 1 . Drilling azimuth: all azimuth angles are $90^{\circ}\left(0^{\circ}\right.$ for the middle line of roadway). Borehole dip angle: coal seam dip angle $+1^{\circ}$. Drilling length: the hydraulic hole drilling is the same as the daily construction, but it needs to be conducted once in the $1 \mathrm{~m}$ section of $15-16 \mathrm{~m}$; the stress test drilling length is $16 \mathrm{~m}$. Drilling diameter: the hydraulic hole drilling is the same as the daily construction; the stress test drilling is $\Phi 55 \mathrm{~mm}$.

\section{Influence Range Analysis of Hydraulic Cavitation}

\subsection{Stress Change Analysis of Surrounding Coal Body}

3.1.1. Stress Data during Punching. Figure 3 shows the relative stress drop values at different intervals during the process of hydraulic cavitation, as shown in Figure 3:

(1) In the process of hydraulic cavitation, the relative stress of the coal seam at the distance of $1.0 \mathrm{~m}$ and $1.5 \mathrm{~m}$ from the cavitation hole decreases significantly, reaching $0.6 \mathrm{MPa}$ and $0.8 \mathrm{MPa}$, respectively, indicating that hydraulic cavitation at the above position has played a relatively good pressure relief effect. As the initial stress value at $1.0 \mathrm{~m}$ is higher than $4.5 \mathrm{MPa}$, the pressure drop is more likely to occur when subjected to coal seam strain. Therefore, the relative stress drop at the distance of $1.5 \mathrm{~m}$ is larger than that at the distance of $1.0 \mathrm{~m}$.

(2) In the process of hydraulic cavitation, the relative stress of the coal seam at the distance of $2.5 \mathrm{~m}$ from the cavitation hole has a certain decrease, which is $0.3 \mathrm{MPa}$, indicating that the hydraulic cavitation can still play a certain pressure relief role at this position, 


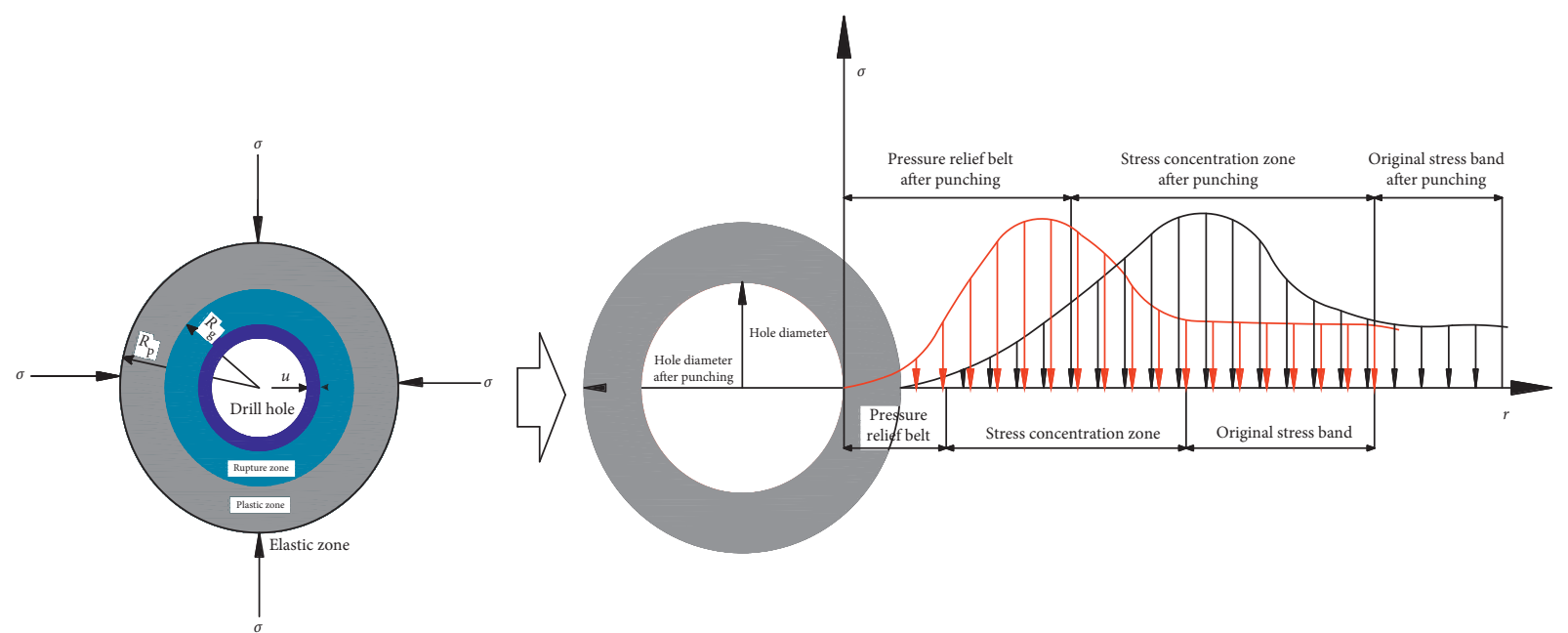

FIGURE 1: Schematic diagram of stress change before and after acupoint making.

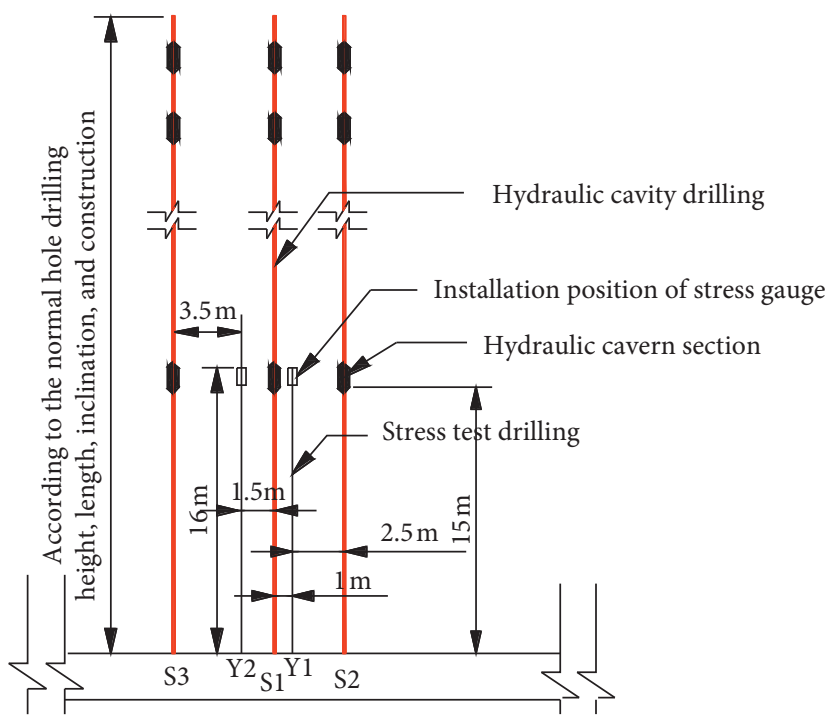

FIgURE 2: Layout plan of test boreholes.

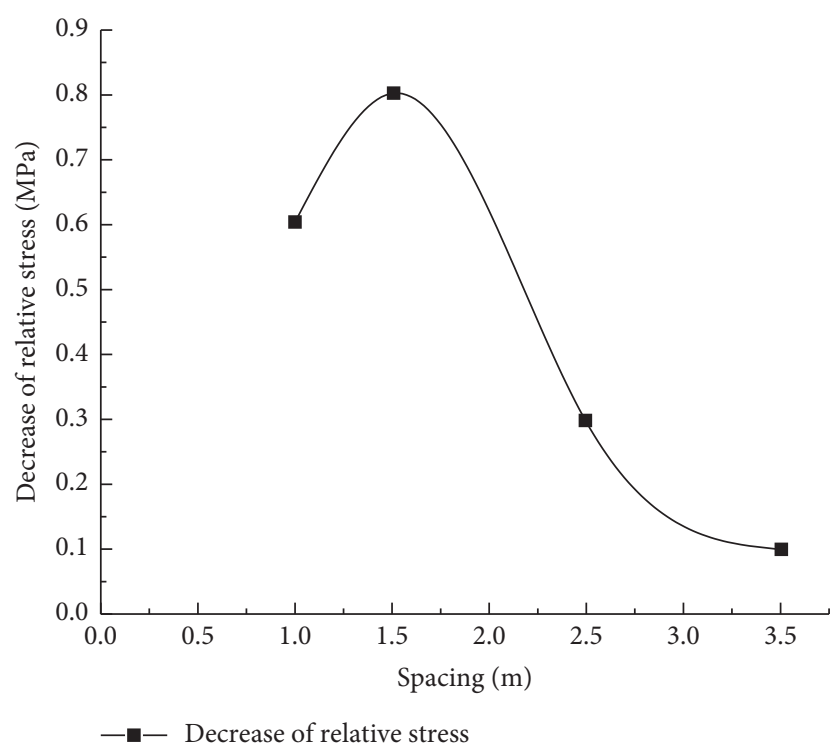

Figure 3: Relative stress drop values at different spacing. 
but it is weaker than that at the distance of $1.0 \mathrm{~m}$ and $1.5 \mathrm{~m}$.

(3) In the process of hydraulic cavitation, the relative stress of the coal seam at the $3.5 \mathrm{~m}$ interval of the cavitation hole almost does not decrease, which is only $0.1 \mathrm{MPa}$, indicating that the pressure relief effect caused by hydraulic cavitation at this position is very weak.

3.1.2. Stress Data after Punching. After hydraulic cavitation, the relative stress data at different distances were continuously tracked, and the variation of the relative stress values with time was analyzed, as shown in Figure 4.

(1) At $1.0 \mathrm{~m}$ and $1.5 \mathrm{~m}$ spacing between cavitation holes, the relative stress of coal seam decreases obviously, and the decrease speed is fast, the decrease duration is long, and the decrease amount is large. The decrease amount at the distance of $1.0 \mathrm{~m}$ and $1.5 \mathrm{~m}$ from the cavitation hole is $2.0 \mathrm{MPa}$ and $1.1 \mathrm{MPa}$, respectively. At a $1.0 \mathrm{~m}$ interval, the decrease rate is $0.049 \mathrm{MPa} / \mathrm{h}$, and the decrease rate is stable after $41 \mathrm{~h}$. After a continuous decrease for $31 \mathrm{~h}$ at a distance of $1.5 \mathrm{~m}$, the decrease rate is $0.035 \mathrm{MPa} / \mathrm{h}$. It shows that the pressure relief effect in the above area is very obvious.

(2) At the $2.5 \mathrm{~m}$ spacing of cavitation holes, the relative stress of coal seam drops relatively small, and the amount of decrease is $0.3 \mathrm{MPa}$. It remains stable after a continuous decrease for $22 \mathrm{~h}$, and the rate of decline is $0.014 \mathrm{MPa} / \mathrm{h}$. The decrease time is short and the rate of decline is low, indicating that the pressure relief effect here is weaker than that at the $1.0 \mathrm{~m}$ and $1.5 \mathrm{~m}$ spacing.

(3) At the $3.5 \mathrm{~m}$ spacing of cavitation holes, the relative stress of coal seam drops less, with a decrease amount of $0.2 \mathrm{MPa}$, which remains stable after a continuous decrease of $20 \mathrm{~h}$ and a decline rate of $0.010 \mathrm{MPa} / \mathrm{h}$, indicating that the pressure relief effect here is weaker than that at the $2.5 \mathrm{~m}$ spacing.

According to relevant studies, the change rule of permeability coefficient of coal seam around hydraulic cavitation drilling is as follows:

$$
\lambda=\left\{\begin{array}{cl}
\lambda^{\prime}, & r=r_{0}, \\
\frac{K}{4 \mu p_{n}}+\frac{\lambda^{\prime}}{2} e^{-a r}, & r_{0}<r<L, \\
\lambda_{0}, & r \geq L .
\end{array}\right.
$$

$\lambda^{\prime}$ is the permeability coefficient of the borehole wall, $\mathrm{m}^{2} /$ $\left(\mathrm{MPa}^{2} \cdot \mathrm{d}\right) ; \lambda_{0}$ is the permeability coefficient of the original coal seam, $\mathrm{m}^{2} /\left(\mathrm{MPa}^{2} \cdot \mathrm{d}\right) ; L$ is the stress distribution range of borehole surrounding rock, $\mathrm{m} ; r_{0}$ is the borehole radius of line cavitation, $\mathrm{m}$; $p_{n}$ is atmospheric pressure, $0.101325 \mathrm{MPa}$; $K$ is the permeability of coal, $\mathrm{m}^{2} ; u$ is the dynamic viscosity coefficient, $\mu=1.08 \times 10^{-5} \mathrm{~Pa} \cdot \mathrm{s}$.

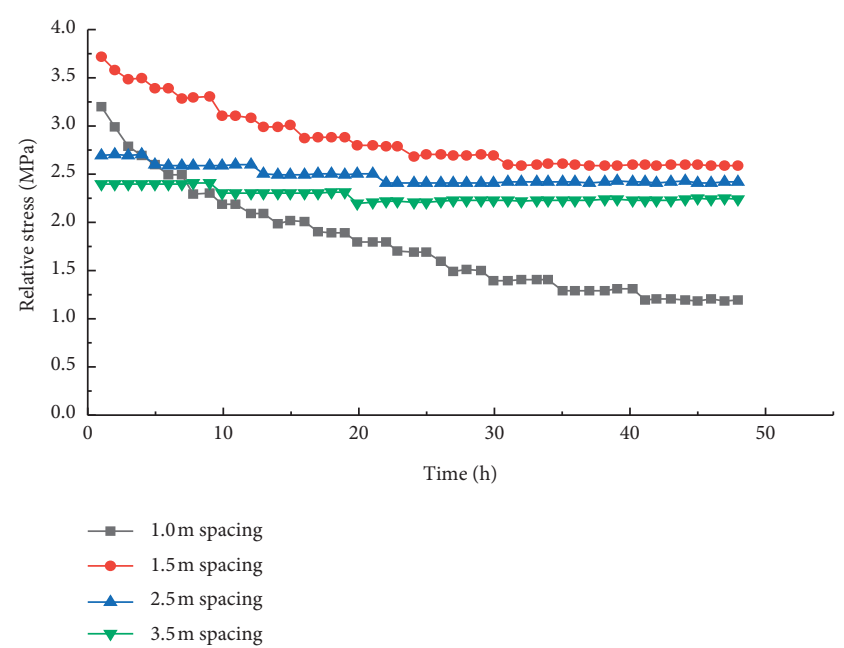

FIgURE 4: Changes of relative stress data at different spacing with time after hydraulic cavitation.

According to the above equation, hydraulic made hole drilling hole wall of the coal seam permeability coefficient is the largest, extending outward along the borehole diameter direction of the broken zone, plastic zone of coal gas permeability coefficient of the original coal seam permeability is obviously improved and made the hole stress, high coefficient of permeability of coal seam is the broken zone, and the plastic zone is on the decline and gradually tends to be the original coal seam permeability coefficient.

In conclusion, with the increase of the distance, the pressure relief effect of hydraulic cavitation on the surrounding coal decreases. The pressure relief effect can be obvious at $1.0 \sim 2.5 \mathrm{~m}$, while the pressure relief effect is very weak after $3.5 \mathrm{~m}$. This is shown in Figure 5.

In order to ensure the safety and efficiency of roadway excavation, the surrounding area of hydraulic hole drilling $>3.5 \mathrm{~m}$, the stress direction and gas content of roadway are large, and the prevention and control measures of "hydraulic and mechanical cavity making + steel screen pipe + surrounding rock grouting" are adopted. There are 8 hole making boreholes in a single drilling field, with a depth of $120 \mathrm{~m}$. The adjacent boreholes start to make holes at $18 \mathrm{~m}$ and $15 \mathrm{~m}$, respectively, and the hole making spacing is $7 \mathrm{~m}$. After verification, it is found that the effective gas fracturing burst pressure to reduce the frequency of coal blasting is more than $190 \mathrm{MPa}$. In order to fully grasp the occurrence of roof strata and bedding and fracture development, the changes of bedding and fracture in borehole before and after fracturing were compared. Before and after fracturing, the borehole imager is used to peep the borehole. The peep image results are shown in Figure 6.

(1) Peep before fracturing: before fracturing, the borehole wall is smooth, bedding and fracture are not developed.

(2) Peep after fracturing:

(1) The maximum peeping depth of the hole peeper is $17 \mathrm{~m}$, and the part with the hole depth greater than $17 \mathrm{~m}$ cannot be observed temporarily. 


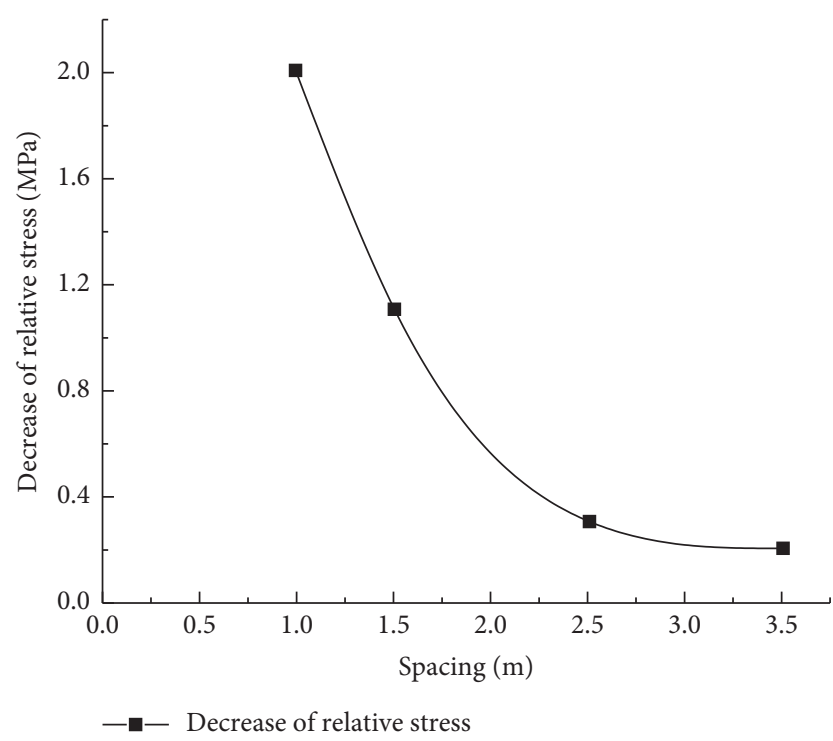

Figure 5: Relative stress drop values at different spacing.

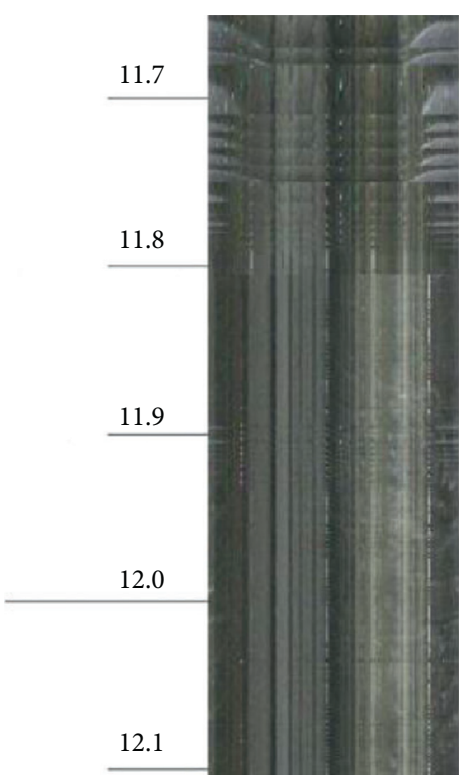

(a)

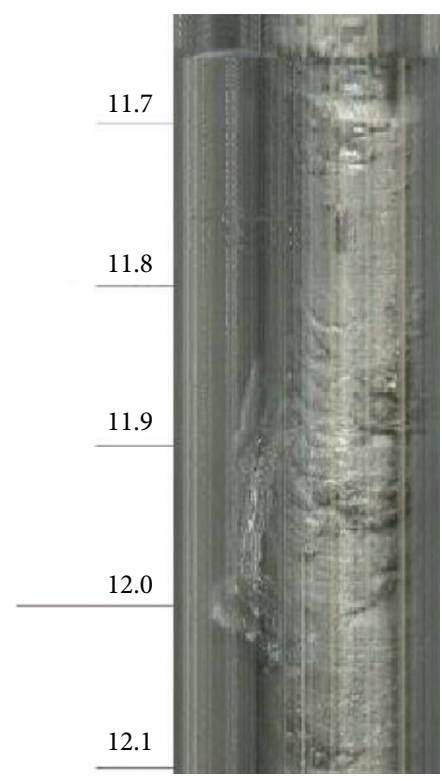

(b)

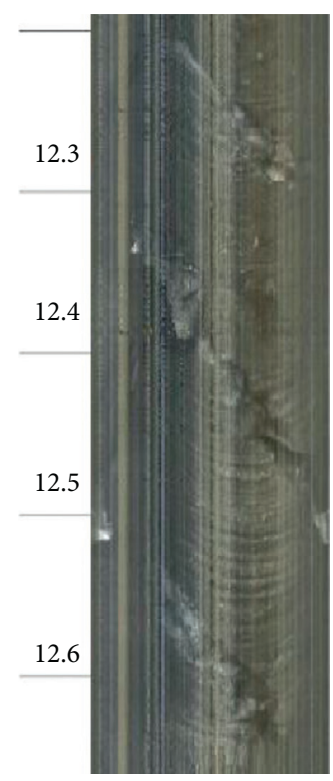

(c)

Figure 6: Peep image (a) before fracturing, (b) after fracturing, and (c) 7 days after fracturing.

(2) The number of microfractures, fracture expansibility, and fracture number increase significantly in the fracturing area.

(3) On the seventh day after fracturing, the fractures closed obviously and the dynamic events of surrounding rock began to increase.

3.2. Spectrum Analysis of Microseismic Events in Hydraulic Cavitation of Coal Roadway. Coal and rock dynamic disasters occur in large intensity and are highly destructive. Coal and gas outburst is one of the biggest coal and rock dynamic disasters in mine production, which seriously threatens the safe mining of the mine [16]. Underground mining disturbance induces coal and rock to release a large amount of elastic energy and high gas internal energy. Under such conditions, the possibility of coal outburst is greater and the probability of coal and rock dynamic disasters is also greater [17]. In order to reveal the relationship between thelaw of seismic activity and the change of stress before and after hole making,the Canadian ESG microseismic monitoring system is used to monitor the wholeprocess of driving roadway and summarize and analyze the data and the temporal andspatial evolution process of microseismic events before and after hole making, and the qualitative analysis of roadway surrounding seismic dynamic response waveform signal spectrum characteristics and 
implementation of rock burst signal remote, real-time, dynamic, automatic monitoring identify each time the vibration of the vibration types and judge the stress source of microseismic events to face danger degree evaluation. Table 1, for February 19-29 coal mine ring number and position, from February 19 to 24, shows the underground coal and cannons, 44 noise cannons according to the noise source and noise microseismic monitoring system for real-time positioning from the roof and the ram position, monitoring of more than 40 significantly coal YanWei burst incidents, and calculation of wavelet packet energy $1.00 e+07 \mathrm{~J}$ above 26 , February 21, which is thus around roadway roof where microfracture occurs, the highest energy at $3.6 e+09 \mathrm{~J}$. In this case, the miner has successively adopted hydraulic cavitation to relieve pressure on the coal seams from many sources in the roadway. After the implementation, 21 sound coal cannons were recorded from February 25 to 29, and only 11 microseismic events with obvious power were statistically found, with small sound and energy. In addition, it is found that the frequency of crosstalk is the most frequent at $8 o^{\prime}$ clock every day. The main reason is that $8 o^{\prime}$ clock is the main driving time. During this time, the driving speed is accelerated, the fault zone of the coal roadway is active, and the coal gun is fired. As can be seen from Figure 7, after adopting hydraulic cavitation to relieve the danger, both the gas content and gas pressure in the coal seam are released, and the number of underground sounding coal gunners and microseismic events is significantly reduced. It can be seen that this measure can keep the internal stress in the coal seam in balance and has a good effect on maintaining the stable state of the roadway and accelerating the driving speed.

Research shows that coal and rock dynamic disasters often occur in the axis of anticline and syncline, especially near faults, coal seam dip angle change zone, coal seam fold, and tectonic stress zone [18]. 8006 transport lane is located in an active fault zone, the coal seam inclination of the roadway is $4-14^{\circ}$, the tunneling face is close to the Eastern Zhou anticline, the geological structure is complex, the excavation activity caused by the increase of fault shear stress and the decrease of normal stress is likely to induce mine seismic activity, with the continuous advancement of tunneling work, and the roof activity is intense. According to the dynamic event microseismic signal of coal and rock in the roadway, the short-time Fourier transform and wavelet packet transform are used to analyze the spectrum characteristics. The short-time Fourier transform (STFT) is derived from the classical Fourier transform, on the basis of which the time window function is added. STFT overcomes the interference of cross term in nonstationary signal analysis and is a powerful tool for nonstationary signal analysis. The expression is in the following form, including $t=\tau$ :

$$
\operatorname{STFT}(\tau, f)=\int_{-\infty}^{\infty} h(t) g(t-\tau) e^{(-2 i \pi f)} t \mathrm{~d} t,
$$

where $f$ is the frequency, $H(t)$ is the analyzed signal, $g(t)$ is the window function, and $T$ is the time.
Figure 8 shows seismic signal spectrum analysis of coal and rock burst. As shown in Figure 7 (February 21-24), three times more large vibration signals, where, on February 21 , roadway roof fracture happens, analyze the acquisition signal where the signal length is about $0.4-0.5$ milliseconds, there is the short duration of the signal and large amplitude (has reached the maximum amplitude of sensor that can accept $4096 \mathrm{mv}$ ), the signal total energy is $3.6 e+09 \mathrm{~J}$, the wavelet package signal energy is concentrated in the first band, since 2-band energy gradually decreased, and 16-band wavelet packet energy almost reduced to $0 \mathrm{~J}$. Therefore, it is ruled out that internal microfracture signal occurs in coal and rock mass. For further analysis, reasons of roof fracture to provide theoretical support for XieWei measures and the monitoring signal Fourier transform to get the signal frequency of $250 \mathrm{~Hz}$ satisfy large intensity spectrum characteristics of vibration signals, and by the $S$ transformation of its verification, it was found that the strength of large rupture occurred ahead of the side of roadway roof rock mass, rock burst, support, and pressure transfer to coal.

According to the analysis of coal and rock fracture that occurred from 21 to 24 and formulate measures to relieve the danger, hydraulic cavitation was adopted to relieve the pressure in the roadway. After the measures were adopted, three obvious coal and rock dynamic phenomena occurred successively from 25 to 29 days. Figure 9 makes hydraulic hole after microseismic signal spectrum analysis, discovered by Figure 8 after the hydraulic hole builds microseismic signal waveform amplitude slash, remaining within the $2000 \mathrm{mv}$, of which $200-800 \mathrm{mv}$, the signal frequency is obtained by Fourier transform concentrated in about $200 \mathrm{~Hz}$, mostly in $200 \mathrm{~Hz}$, significantly lower than building hole before the main frequency, and the frequency range is also greatly narrowed; through the frequency domain analysis of S-transform, it is found that the main frequency points of surrounding rock dynamic events are low after hydraulic cavern building; most of them are caused by small coal rock falling, which will not affect the normal driving of coal roadway. Visible XieWei measures after execution and the coal and rock dynamic events are small rock failure or tunneling roadway coal drop ahead and will not affect drivage work, also not to endanger the safety of staff and facilities of the safety of life.

\subsection{Moisture Change Analysis of Surrounding Coal. After the} hydraulic measures, the surrounding coal mass moves toward the borehole, causing the crack expansion, and at the same time, the high-pressure water will also flow along with the crack expansion to supplement the water of the coal seam [19-21]. Therefore, the water replenishment range of coal seam is approximately consistent with the crack expansion range. Since the crack extension range directly measured in the coal wall of the working face is affected by the visible width of the crack and the continuous expansion of mining-induced stress [22, 23], the reliability of the measured crack extension range is not high (as shown in Figure 10, only obvious cracks can be observed and it is 
TABLe 1: Statistics of noise coal gun in the roadway.

\begin{tabular}{|c|c|c|c|c|}
\hline Date & $\begin{array}{l}\text { Frequency of } \\
\text { sound }\end{array}$ & $\begin{array}{l}\text { Frequent noise } \\
\text { frequency }\end{array}$ & $\begin{array}{l}\text { Sound } \\
\text { frequency }\end{array}$ & Position \\
\hline February 20th & 12 & 8 o'clock & 6 & Middle of roof \\
\hline February 21th & 2 & 4 o'clock & 1 & Roof fracture \\
\hline February 22th & 2 & 8 o'clock & 2 & - \\
\hline February 23th & 13 & 8 o'clock & 8 & Wind tunnel gang \\
\hline February 24th & 15 & 8 o'clock & 7 & There are 4 air ducts and two pedestrians \\
\hline February 25th & 13 & 8 o'clock & 9 & $\begin{array}{l}\text { Air duct, pedestrian, } 10-15 \mathrm{~m} \text { from head to back } 10- \\
15 \mathrm{~m}\end{array}$ \\
\hline February 26th & 2 & 8 o'clock & 9 & - \\
\hline February 27 th & 6 & 4 o'clock & - & - \\
\hline $\begin{array}{l}\text { February } 28- \\
\text { 29th }\end{array}$ & 0 & - & - & - \\
\hline
\end{tabular}

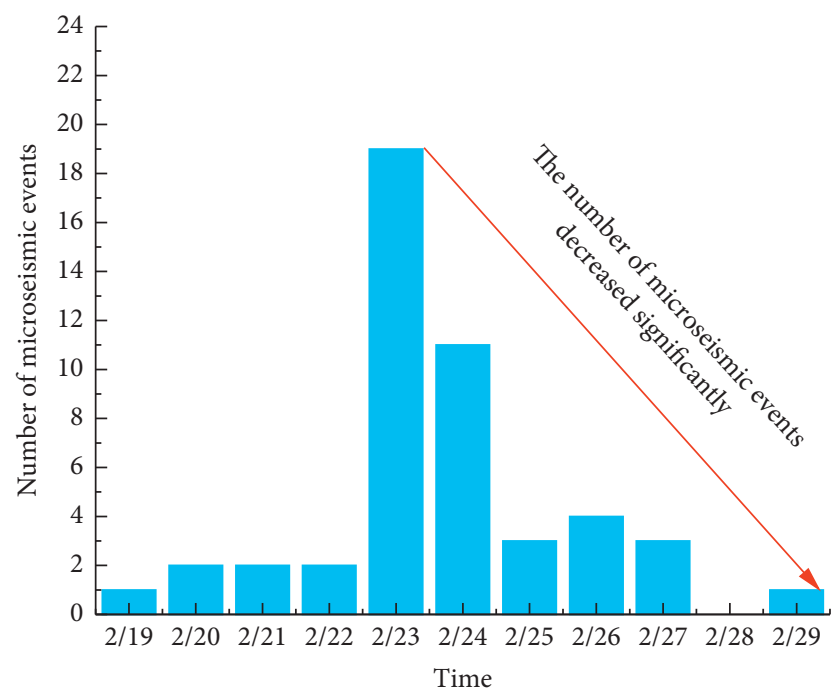

Figure 7: Diagram of the daily number of microseismic events.
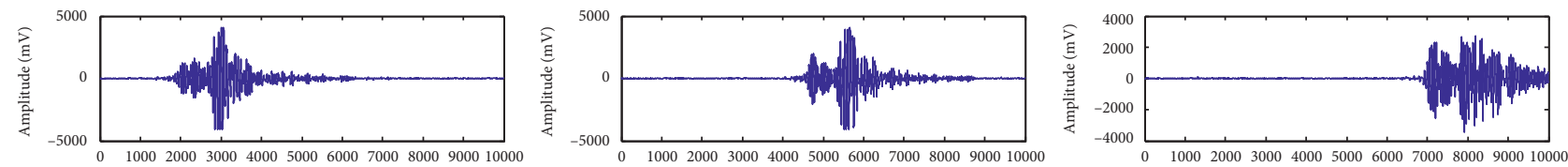

Time (points)

Time (points)

Time (points)
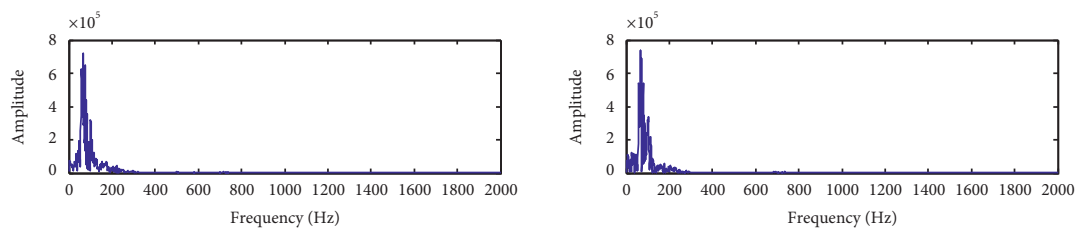

(a)

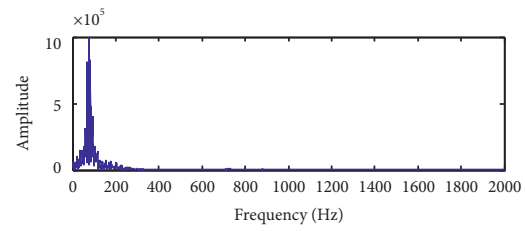

FIgURE 8: Continued. 

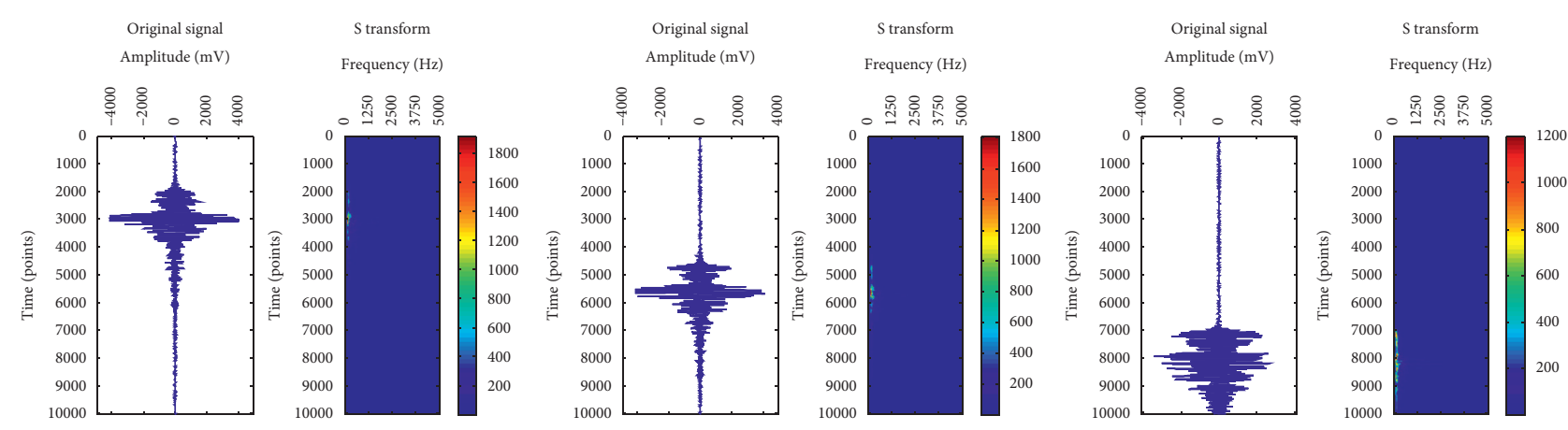

FIgURE 8: Spectrum diagram of coal rock fracture signal from February 21 to 24. (a) Fourier transform results of coal rock fracture. (b) Stransform results of coal rock fracture.
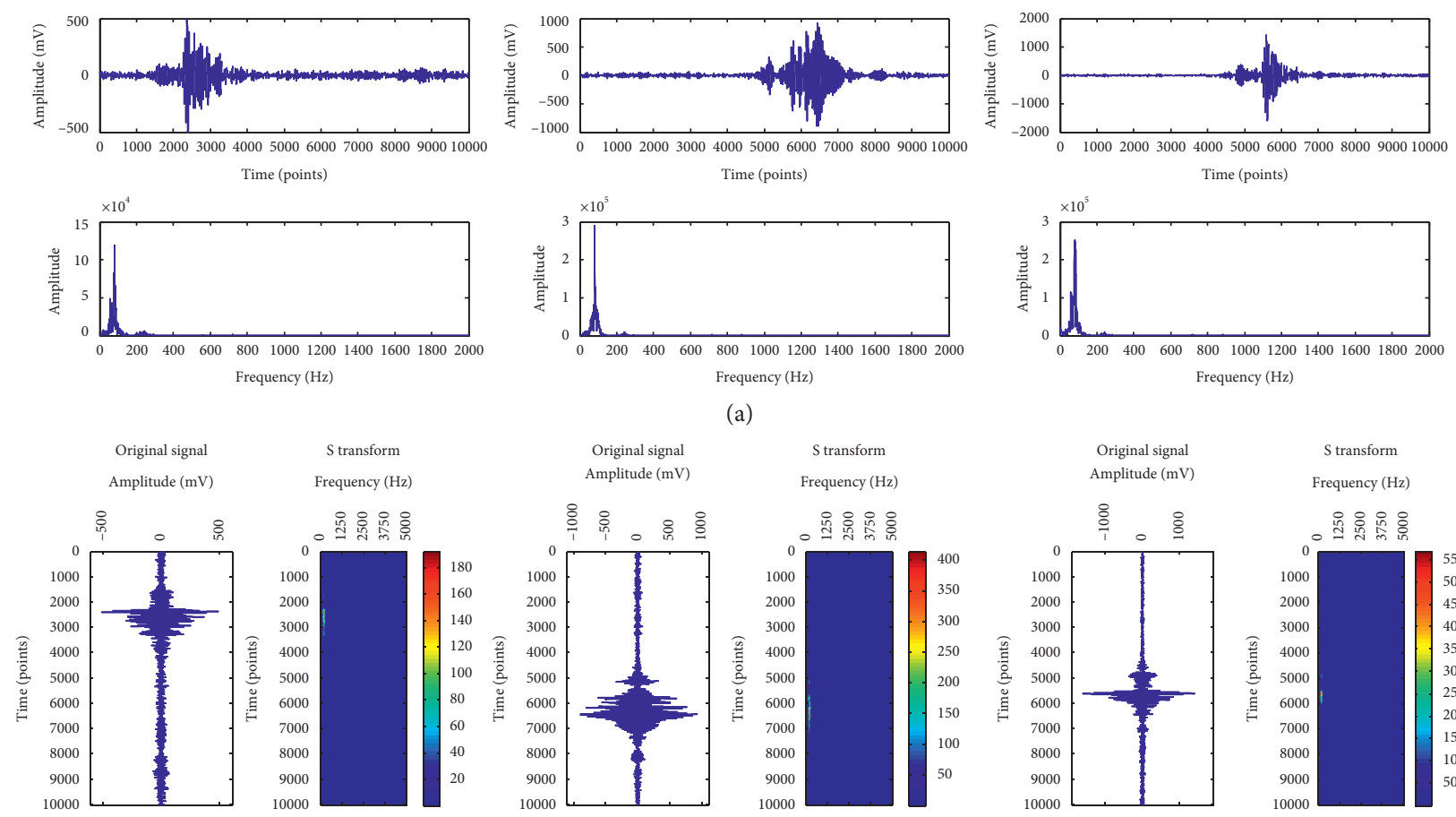

$$
\begin{gathered}
\text { S transform } \\
\text { Frequency }(\mathrm{Hz})
\end{gathered}
$$

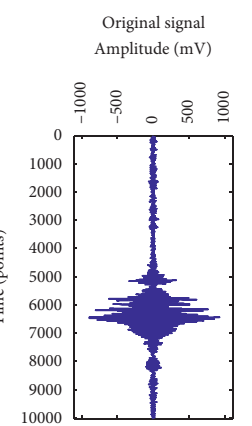

(a)
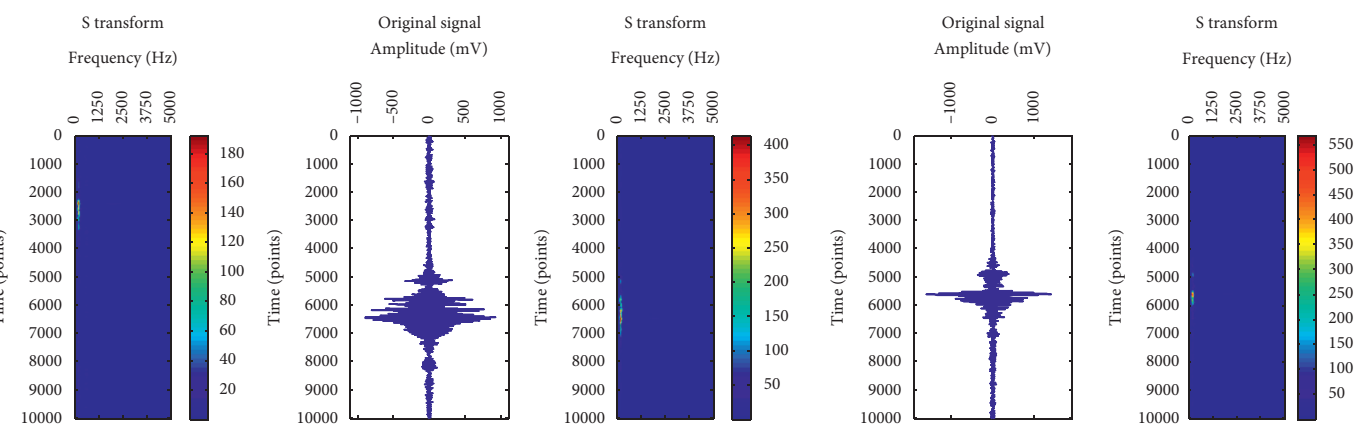

(b)

FIGURE 9: Frequency spectrum characteristics of microseismic signals after hydrocavern building. (a) Fourier transform results of coal rock fracture. (b) S-transform results of coal rock fracture.

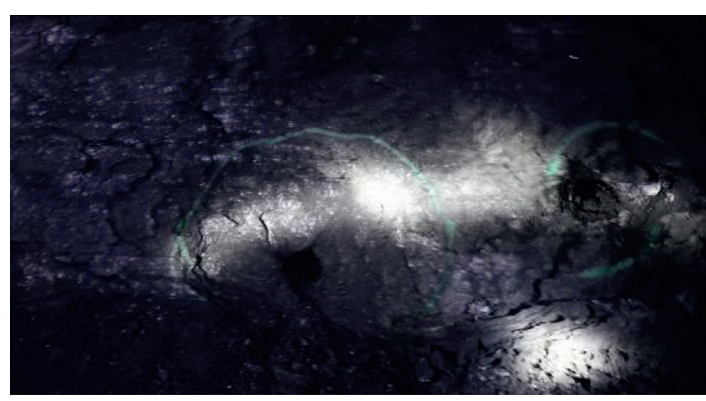

(a)

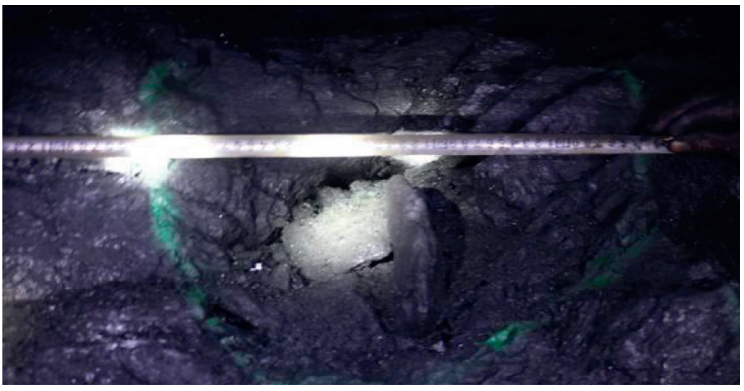

(b)

Figure 10: Fracture expansion range. (a) The distance between the two hole making holes is $3 \mathrm{~m}$, and the cracks are completely connected. (b) The diameter of a single hole is $0.7 \mathrm{~m}$, and it has collapsed after coal cutting. 
difficult to determine the cause of the crack), so the water test is used to calculate the coal seam water supply range.

According to the data in Figure 11, it can be seen that the average moisture of coal seam within the test range increases from $1.09 \%$ of raw coal to $3.16 \%$, and the maximum reaches $5.15 \%$. During the test, considering the influence of two ordinary holes in the middle of the roadway, the radius of the test area was $1.1 \mathrm{~m}$, and the water content at the edge of the test area was still far greater than that of the raw coal. According to the variation law of each water test point, the radius of the water replenishing range was $1.5 \mathrm{~m}$, so the water replenishing range of the working face by the hydraulic cavitation release hole technology exceeded $79 \%$ of the area of the coal wall.

On the one hand, hydraulic cavitation release drill plays the role of pressure relief and reflection improvement, speeding up the release of gas from the broken coal body, and on the other hand, it also plays the role of water replenishing and wetting the coal body around the cave and inhibiting the desorption of gas from the wet coal body [24-27]. After sampling at the opening of 8006 return air roadway, the coal sample with $0.17-0.25 \mathrm{~mm}$, and the particle size was obtained from No. 3 coal seam of Wuxiang Coal Mine through grinding. Natural desorption experiments of coal under different moisture and unified equilibrium pressures were carried out. The variation curve of gas desorption velocity over time is shown in Figure 12.

The following can be seen from the above experimental results:

(1) The desorption law of coal samples with different water contents conforms to the power exponential function. (2) The coal sample with $1 \%$ moisture has the highest coalbed methane desorption rate, and the fitting coefficient $B$ value reaches 1.7233 , which indicates that the methane desorption of coal sample with $1 \%$ moisture has the characteristics of high initial gas desorption rate and fast decay rate. With the increase of water content, the $B$ value of the injected coal samples decreased from 1.7233 to 0.9342 , which indicated that water injection affected the desorption rate of methane in the coal samples, making the initial desorption rate smaller and the attenuation rate slower. The initial desorption velocity is reduced by water injection, and the desorption process becomes more gentle, avoiding the sudden release of a large amount of coalbed methane. (3) With the increase of water content, the initial gas desorption velocity $B$ value decreases continuously. The decrease of the initial gas desorption rate in the water-injected coal sample can effectively prevent the sudden and massive gas desorption, which is beneficial to the prevention and control of coal and gas outbursts. With the increase of moisture, the attenuation rate slows down, and the desorption of methane in coal becomes more uniform, and it is not easy to release a large amount of methane in case of a slight disturbance.

The above experimental results are the important reason for the slow attenuation of the extraction pure volume of hydraulic cavitation borehole and the fundamental reason for the low gas concentration in the backflow during coal cutting in the tunneling face under the action of hydraulic cavitation release hole.
3.4. Analysis of Gas Change in Surrounding Coal. Through the statistical analysis of the content test results of 8006 air-return roadway and haulage roadway and the airreturn flow data of developing face, it is found that the content is not the root cause affecting the air-return flow concentration of developing face, but the root cause lies in the desorption characteristics of coal in a short time. The coal breaking process during coal cutting is the direct reason for the increase of gas concentration in return for air flow. Generally, the whole coal cutting time lasts about 40 minutes, and the coalbed methane sources include free gas in the coal body, $W 1+W 2$, and fresh head-on natural release. Table 2 shows the comparison of gas content test results after taking danger relief measures.

According to the calculation formula of coalbed methane content, various indexes of coal content and free gas in the 8006 air-return roadway and haulage roadway are obtained.

$$
x=\frac{a b p}{1+b p} \times \frac{100-A_{d}-M_{a d}}{100} \times \frac{1}{1+0.31 M_{a d}}+\frac{10 \pi p}{\gamma} .
$$

In the formula, $x$ is the residual gas content of coal seam, $\mathrm{m}^{3} / \mathrm{t} ; a$ and $b$ are the adsorption constant; $p$ is the residual gas pressure of coal seam, $\mathrm{MPa} ; A_{d}$ is the ash content of coal, $\% ; M_{a d}$ is the moisture of coal, $\% ; \pi$ is the porosity of coal, $\mathrm{m}^{3} / \mathrm{m}^{3} ; \gamma$ is the bulk density of coal proportion (false), $\mathrm{t} / \mathrm{m}^{3}$.

Among them $(a b p /(1+b p)) \times\left(\left(100-A_{d}-M_{a d}\right) /\right.$ $100) \times\left(1 /\left(1+0.31 M_{a d}\right)\right) \cdot 10 \pi p / \gamma$ is adsorbed gas and free gas.

As shown in Table 2, after the implementation of hydraulic hole making and hazard relief measures, the free gas content, fresh head natural gas release content, gas pressure, and total gas released by coal body during coal cutting have been reduced. It can be seen that hydraulic hole punching and hazard relief measures have a good effect on reducing gas content.

\section{Results and Analysis}

Based on the test and research background of 8006 haulage roadway in the Wuyang Coal Mine expansion area, this paper analyzes the influence scope of hydraulic punching and the stress transformation of surrounding coal body by arranging stress test boreholes and hydraulic hole making boreholes in different directions; it is found that the pressure relief effect of hydraulic cavitation on surrounding coal decreases with the increase of distance, and the pressure relief effect is obvious at $1.0-2.5 \mathrm{~m}$, but it is very weak after $3.5 \mathrm{~m}$; meanwhile, the water content of coal seam is greatly increased by hydraulic cavitation measures, the maximum water content reaches $5.15 \%$, and the radius of water supplement for coal seam is $1.5 \mathrm{~m}$. Combined with microseismic monitoring technology, the intensity change of coal rock dynamic events before and after hydraulic cavern building was analyzed. It was found that the amplitude of microseismic signal waveform decreased greatly after hydraulic cavern building, the frequency also decreased from above $250 \mathrm{~Hz}$ to about $150 \mathrm{~Hz}$, and the intensity of coal rock 


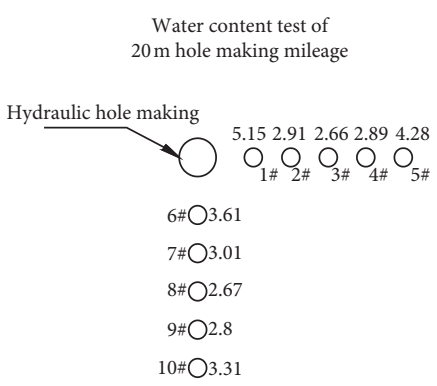

(a)

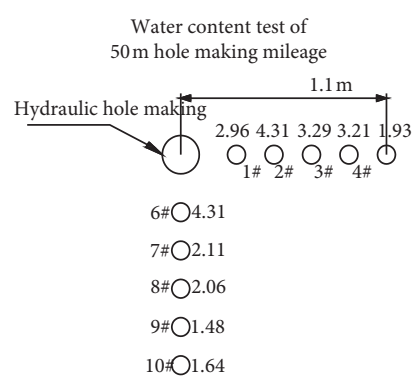

(b)

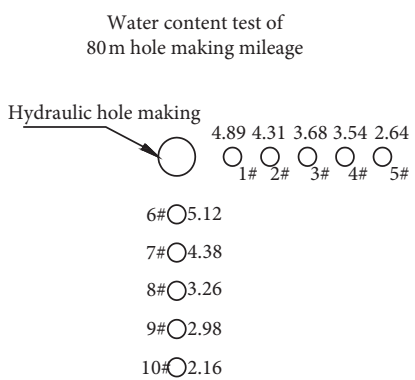

(c)

FIGURE 11: Water supplement of coal seam around cavern forming a hole at (a) $20 \mathrm{~m}$, (b) $50 \mathrm{~m}$, and (c) $80 \mathrm{~m}$ of cavern forming mileage.

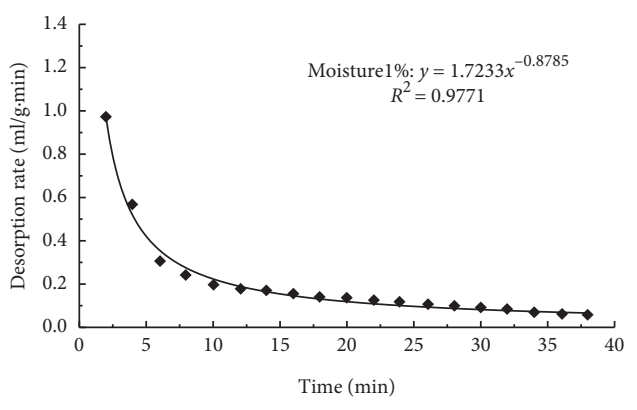

(a)

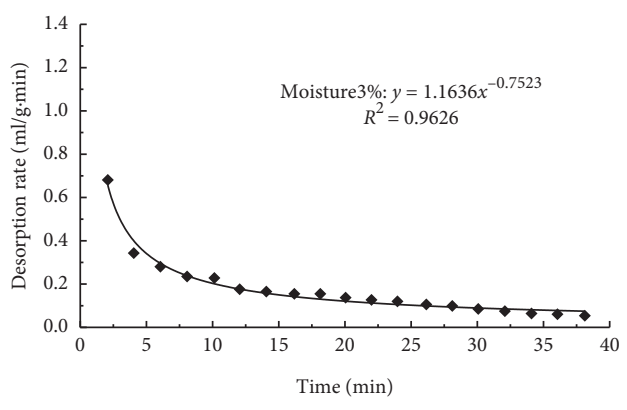

(b)

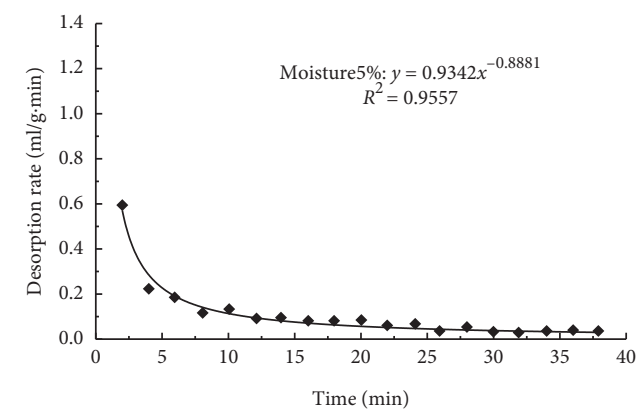

(c)

FIGURE 12: Gas desorption rate of coal sample under different moisture conditions (gas desorption speed when equilibrium pressure is $2.5 \mathrm{MPa}$ and water content is $1 \%, 3 \%$, and $5 \%$ ).

TABLE 2: Comparison of gas content test results after taking measures.

\begin{tabular}{lccccccc}
\hline Test tunnel & $\begin{array}{c}\text { Before and after } \\
\text { the measures }\end{array}$ & $\begin{array}{c}\text { Average } \\
W 1+W 2\end{array}$ & $\begin{array}{c}\text { Average } \\
W\end{array}$ & $\begin{array}{c}\text { Average } \\
W 3 \mathrm{~m}^{3} / \mathrm{t}\end{array}$ & $\begin{array}{c}\text { Pressure } \\
\mathrm{MPa}\end{array}$ & $\begin{array}{c}\text { Free } \\
\text { gas }\end{array}$ & $\begin{array}{c}\text { During coal cutting total } \\
\text { amount of gas released from } \\
\text { coal }\end{array}$ \\
\hline 8006 air- & Before & 4.06 & 14.33 & 7.60 & 1.56 & 0.38 & 4.06 \\
return & After & 2.61 & 12.14 & 7.17 & 1.02 & 0.25 & 2.61 \\
8006 & Before & 4.16 & 14.38 & 8.42 & 1.38 & 0.35 & 4.16 \\
haulageway & After & 3.08 & 12.90 & 7.44 & 1.10 & 0.28 & $3.08<X<3.36$ \\
\hline
\end{tabular}

dynamic events was far less than that before hydraulic cavern building and pressure relief. Based on the analysis of water content and coalbed methane change of coal body around the hydraulic cavern, it is found that hydraulic cavern can effectively prevent a sudden large amount of coalbed methane desorption, which is very beneficial to the prevention and control of coal and coalbed methane outburst. The research shows that the hydraulic cavity can release the pressure of coal seam coalbed methane greatly, keep the roadway stable, and improve the driving speed. However, the selection of test sites is limited, the spatial analysis of coal and rock dynamic events monitored by the microseismic monitoring system is not deep enough, and the research on the relative position relationship between coal and rock dynamic events and hydraulic cavern formation is not specific enough. This part should be emphasized in the follow-up research. 


\section{Conclusion}

(1) The paper makes a comparative analysis of the stress variation of coal seam during and after hydraulic cavitation and finds that the relative stress of coal seam decreases gradually with the extension of time, and the pressure relief effect gradually appears. In the range of less than $2.5 \mathrm{~m}$ around the hydraulic hole drilling, the pressure relief duration is long, the pressure relief rate is fast, and the pressure relief amplitude is large. The pressure relief effect of hydraulic hole drilling is the best. In the range of 2.5-3.5 $\mathrm{m}$ around the hole, the duration, rate, and amplitude of pressure relief are reduced. Although the hydraulic cavity can produce a certain pressure relief effect, it is relatively weak. Within the range of above $3.5 \mathrm{~m}$ around the hole, the available pressure relief effect can hardly be observed.

(2) Through the analysis of the moisture change of the surrounding coal body during hydraulic cavitation, the conclusions are as follows: during the process of drilling, the coal body in the face of the working face is basically communicated through the cavity making fissures, and the free coalbed methane also dissipates through these fissures in advance. However, the disturbance of the common hole to the coal seam is far less than that of the hydraulic hole. The hydraulic hole making and releasing technology is of great significance to the construction. The head-on water supply scope of the working face should exceed $79 \%$ of the coal wall area.

(3) Through time-frequency analysis of tunnel microseismic events before and after hydraulic cavitation found that the main frequency of coal rock fracture signal before hydraulic cavern building is about $250 \mathrm{~Hz}$, and the signal is continuous. Multiple groups of signals are similar, with rapid attenuation, short duration, high main frequency, large specific gravity value, large signal duration, and released energy. It shows that the impact of microseismic events will cause the sudden increase of deformation energy of surrounding rock of mine roadway and cause largescale damage events, which will cause the collapse of coal rock. With the increase of coalbed methane content and coalbed methane pressure, the intensity of coal rock fracture dynamic event is greatly weakened after the implementation of hydraulic cavitymaking measures, which shows that this measure has a good effect on coal seam pressure relief.

\section{Data Availability}

The data used to support the findings of this study are included within the article.

\section{Conflicts of Interest}

The authors declare that there are no conflicts of interest regarding the publication of this article.

\section{Acknowledgments}

The authors are grateful for the financial support of the research from the National Natural Science Foundation of China (51704101), Key Scientific and Technological Research Projects in Henan Province (182102310780 and 192102310199), and the 65th General Program of China Postdoctoral Science Foundation (2019M6525352536), supported by "the Fundamental Research Funds for the Universities of Henan Province (NSFRF200307).

\section{References}

[1] H. Wang, X. Fang, F. Du et al., "Three-dimensional distribution and oxidation degree analysis of coal gangue dump fire area: a case study," The Science of the Total Environment, vol. 772, Article ID 145606, 2021.

[2] R. Zhiyuan, J. Yang, and Y. Zhaoguo, "Application of shallow hole loosening blasting in geological disaster control engineering," Chinese Journal of Underground Space and Engineering, vol. 6, no. z2, pp. 1696-1698, 2010

[3] S. Biming and Yu Qixiang, "Analysis of outburst prevention effect of deep hole pre-cracking control loosening blasting in low air permeability coal seams," Mine Construction Technology, vol. 5, pp. 27-30, 2002.

[4] Z. Fujun, "Application of loose blasting in coal mining," Blasting, vol. 19, no. 1, pp. 40-42, 2002.

[5] Z. Wang and Z. Li, "Research on the elimination mechanism of hydraulic squeeze measures," Safety In Coal Mines, vol. 35, no. 12, pp. 1-4, 2004.

[6] P. Li, "Application of hydraulic extrusion technology in outburst coal seam," Coal Science and Technology, vol. 35, no. 8, pp. 45-47, 2007.

[7] H. Yang and B. Hu, "High outburst coal seam hydraulic extrusion technology application," Coal Science and Technology, vol. 35, no. 6, pp. 31-33, 2007.

[8] L. Ximing and Z. Jing, "Safety analysis of anti-outburst measures for hydraulic cutting," China Mining Magazine, vol. 18, no. 3, pp. 92-99, 2009.

[9] M. Liu, L. Kong, and F. Hao, "Application of hydraulic punching technology in severely outburst coal seams," Journal of China Coal Society, vol. 30, no. 4, pp. 451-454, 2005.

[10] M. Liu, Z. Li, and Y. Liu, "Research on the mechanism of eliminating outbursts of hydraulic cutting measures," Coal, vol. 15, no. 3, pp. 1-2, 2006.

[11] T. Lu, H. Yu, T. Zhou, J. S. Mao, and B. H. Guo, "Improvement of methane drainage in high gassy coal seam using waterjet technique," International Journal of Coal Geology, vol. 79, no. 1-2, pp. 40-48, 2009.

[12] R. Hardy, Acoustic Emission/Microseismic Activity, Vol. 1, A.A.Balkema Publishers, Netherlands, 2003.

[13] Ge Maochen, "Efficient mine microseismic monitoring," International Journal of Coal Geology, vol. 64, no. 8, pp. 44-56, 2005.

[14] W. Jianbin, W. Hongchao, and G. Xiaoliang, “Application by hydraulic flushing cavity technology while drilling in pressure relief hole of low-permeability coal roadway," Coal Technology, vol. 40, no. 2, pp. 72-74, 2021.

[15] J. Zhang, "Application research on technology of hydraulic caving pressure-relief and permeability-enhancement in bottom rock roadway," Safety In Coal Mines, vol. 46, no. 7, pp. 69-72, 2020. 
[16] F. Du, K. Wang, X. Zhang, C. Xin, L. Shu, and G. Wang, "Experimental study of coal-gas outburst: insights from coalrock structure, gas pressure and adsorptivity," Natural Resources Research, vol. 29, no. 4, pp. 2481-2493, 2020.

[17] C. Xin, F. Du, K. Wang, C. Xu, S. Huang, and J. Shen, "Damage evolution analysis and gas-solid coupling model for coal containing gas," Geomechanics and Geophysics for GeoEnergy and Geo-Resources, vol. 7, no. 1, p. 7, 2021.

[18] Li Zhihua, Mechanism of Coal Rock Burst Induced by Fault Slip under Mining, China University of mining and technology, Xuzhou, China, 2009.

[19] T. Shuanglong, W. Qingguo, and Z. Lianjun, “Application of permeability enhancement induced by hydraulic jet cavity in hongyang no. 2 colliery," China Coalbed Methane, vol. 14, no. 4, pp. 39-42, 2017.

[20] W. Yaofeng, He Xueqiu, W. Enyuan, and Y. Li, "Research progress and development tendency of the hydraulic technology for increasing the permeability of coal seams," Journal of China Coal Society, vol. 39, no. 10, pp. 1945-1955, 2014.

[21] Z. Cheng, Li Xianzhong, and Li Quangui, "Research and application of coal seam pulsating hydraulic fracturing pressure relief and permeability enhancement technology," Journal of China Coal Society, vol. 36, no. 12, pp. 1996-2001, 2011.

[22] Li Guoqi, Ye Qing, Li Jian Xin et al., "Theoretical analysis and practical study on reasonable water pressure of hydro-fracturing technology," China Safety Science Journal, vol. 20, no. 12, pp. 73-78, 2010.

[23] L. Yanwei, R. Peiliang, X. Shibai et al., "Analysis of pressurerelief and permeability improvement effect of hydraulic flushing," Journal of Henan Polytechnic University(Natural Science), vol. 28, no. 6, pp. 695-699, 2009.

[24] X. Shibai, Z. Wenwu, L. Yanwei et al., "Effect analysis of rapid outburst elimination by hydraulic punching," Safety In Coal Mines, vol. 36, no. 2, pp. 105-107, 2012.

[25] W. Xinxin, X. Shibai, S. biming et al., "Experiment research on hydraulic borehole flushing in no.13-1 seam of pansan mine," Coal Science and Technology, vol. 39, no. 4, pp. 60-64, 2011.

[26] B. Guoji, Z. Chunru, J. Xugang, and Y. Liu, "Eliminating outburst effect and main influencing factors analysis of hydraulic flushing," J Journal of Henan Polytechnic University(Natural Science), vol. 29, no. 4, pp. 440-443, 2010.

[27] F. Yanjun, "Hydraulic fracturing initiation and propagation," Chinese Journal of Rock Mechanics and Engineering, vol. 30, no. z2, pp. 3169-3179, 2013. 